\title{
The impact of an Education-Based Intervention Program (EBIP) on dyspnea and chronic self-care management among chronic obstructive pulmonary disease patients
}

\author{
A randomized controlled study
}

Ayşe Çevirme, PhD, Gönül Gökçay, PhD student.

\begin{abstract}

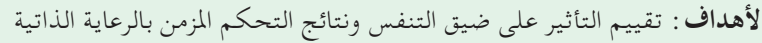

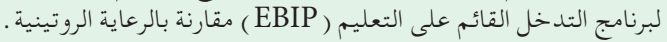

المنهجية : تكون مجتمع الدراسة من مقياس إدارة الرعاية الذاتية لعدد 61 مريضًا

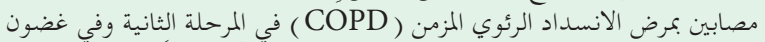

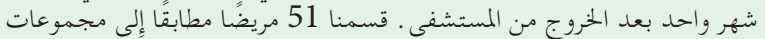

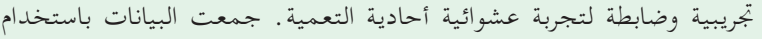

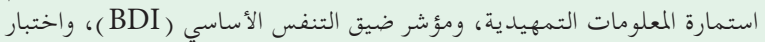

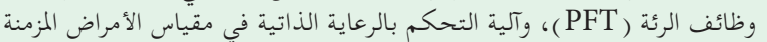
ومؤشر كتلة الجسم ( SCMP_G)

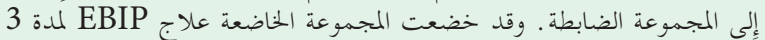

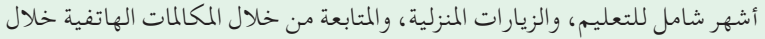

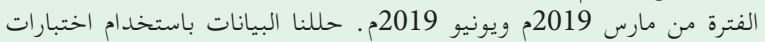

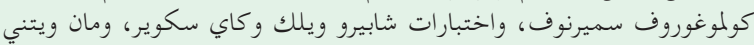

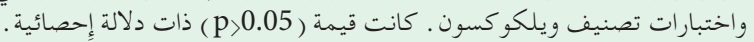

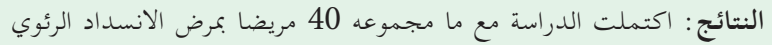

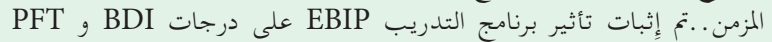
SCMP_G و في مجموعة التدخل إِحصائيًا (

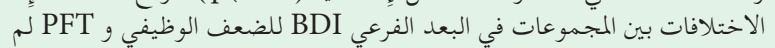

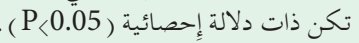

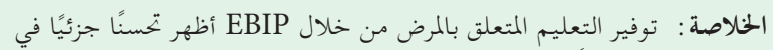

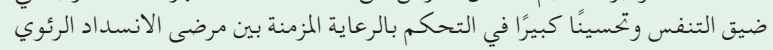
المزمن (COPD) (
\end{abstract}

Objectives: To evaluate the impact of dyspnea and chronic self-care management outcomes of an Education-Based Intervention Program (EBIP) compared to routine care.

Methods: The population of the study consisted of self-care management scale of 61 patients diagnosed with chronic obstructive pulmonary disease (COPD) stage 2 and within one month after discharge. A total of 51 conforming patients were divided into experimental and control groups for a single-blind randomized trial. Data were collected using an introductory information form, the baseline dyspnea index (BDI), pulmonary function test (PFT), the self-care management process in chronic illness
(SCMP-G) scale and body mass index (BMI). There were no addition interventions to the control group. The intervention group underwent a 3-month EBIP intervention that included education, house visits and follow-ups through phone calls between March 2019 and June 2019. The data were analyzed using KolmogorovSmirnov and Shapiro-Wilk tests, $\chi^{2}$, Mann Whitney U and Wilcoxon signed-rank tests. $p<0.05$ was statistically significant.

Results: The study was completed with a total of 40 COPD patients. The effect of the EBIP training program on BDI, PFT, and SCMP-G scores in the intervention group was statistically proven $(p<0.05)$. However, the differences between the groups in the BDI sub-dimension of functional impairment and PFT were not statistically significant $(p>0.05)$.

Conclusion: Providing patients with illness-related education through EBIP provided a partial improvement in dyspnea and a significant improvement in chronic care management among COPD patients.

Keywords: COPD, dyspnea, self-care, nursing, program

Saudi Med J 2020; Vol. 41 (12): 1350-1358

doi: $10.15537 /$ smj.2020.12.25570

From the Department of Public Health Nursing (Çevirme), Faculty of Health Sciences, Sakarya University, Sakarya; and from the Department of Medical Services and Techniques (Gökçay), Kafkas University, Atatürk Health Services Vocational School, Kars, Turkey.

Received 27th July 2020. Accepted 17th November 2020

Address correspondence and reprint request to: Dr. Gönül Gökçay, Department of Medical Services and Techniques, Kafkas University, Atatürk Health Services Vocational School, Kars, Turkey. E-mail: gonul.gokcay@ogr.sakarya.edu.tr ORCID ID: https://orcid.org/ 0000-0003-0140-8668 
C hronic obstructive pulmonary disease (COPD), characterized by progressive airway obstruction, is significantly associated with morbidity and mortality. ${ }^{1,2}$ Being one of the most important symptoms in COPD, the prevention and reduction of dyspnea are integral to standard COPD care. $^{3}$ Previous studies mostly dealt with COPD-specific disease self-management and emphasized non-pharmacological interventions to improve symptom management and quality of life. They also called attention to the effectiveness of pulmonary rehabilitation (PR), disease management, and standardized interventions. ${ }^{4}$ In cases where PR programs cannot be implemented for reasons such as lack of team and equipment (PR structure, local conditions, patient social security, economic conditions), it is required to plan and formulate similar targeted interventions and to investigate the effects of this on dyspnea, self-care management and other symptoms. ${ }^{1}$ There are few studies evaluating the effect of interventional cooperation of health care workers to reduce dyspnea and increase self-care ability of COPD patients, and the available results are inconclusive. ${ }^{4-6}$ Interactive patient training sessions are very useful in improving self-management and increasing knowledge and skills. ${ }^{5}$ According to evidence from GRADE nurse-centered self-management trainings (Cochrane database), it has been found to be of low effect for dyspnea, high effect for health-related quality of life, and moderate effect for hospital admissions for respiratory or any other reasons. ${ }^{7}$ In the study, which agrees with the Oxford Evidence-Based Medical Center data, nurse-based self-management studies provided improvement in the health data of patients. ${ }^{8}$ In addition, it is emphasized that health education given by nurses encourages self-care in individuals with COPD. ${ }^{4}$ However, the most effective approach is still uncertain.

Currently, patients with COPD are provided with training on disease management both in the hospital and at home, and the problem is patient compliance and monitoring in the long run.

Will the nursing-led education-based intervention program (EBIP) help reduce dyspnea and increase chronic self-care management? In this study, we aim to investigate the effect of a EBIP for the development of the 2nd stage COPD drug compliance, breathing exercises,

Disclosure. Authors have no conflict of interests, and the work was not supported or funded by any drug company. proper nutrition, chronic self-care management skills on dyspnea, and chronic self-care management.

Research hypotheses. H0: EBIP has no effect on dyspnea outcomes in COPD patients. H1: EBIP reduces dyspnea outcomes in COPD patients. $\mathrm{H} 0$ : EBIP has effect on chronic self-care management COPD patients. H2: EBIP improves the results of chronic self-care management of COPD patients.

Methods. The study was conducted between March and June 2019 in Kafkas University Hospital, Internal Medicine Clinic, Turkey and patients' homes. A total of 61 stage II COPD patients that were hospitalized and treated in the month of January 2019 were selected for the study. Those who had been discharged for less than a month and resided downtown were included.

The inclusion criteria were as follows: a) diagnosed with stage II COPD for at least 6 months; b) Forced expiratory volume in one second (FEV1) value between 50 and $79 ;^{1}$ c) conscious and oriented; d) can be contacted and can access the hospital. The exclusion criterion was: a) comorbidity. The termination criteria were as follows: a) unwilling to participate; b) admission to a different hospital; c) not presenting for posttests.

Thestudy was granted an ethical approval by the Kafkas University Medical Faculty Non-Interventional Ethics Committee (date:30/01/2019, decision number: 01) and ClinicalTrials.gov as NCT04260178. All patients have signed informed consent forms. Necessary permissions have been obtained for the use of scales. The study was carried out according to the principles of the Declaration of Helsinki.

The study was designed as a randomized pretestposttest controlled trial. Intervention and control groups were evaluated with an introductory survey form, bazal dyspnea index (BDI), pulmonary function tests (PFT), self-care management scale in chronic diseases (SCMP-G), and body mass index (BMI), before and after the intervention. The intervention group underwent an EBIP. There were no additional interventions to the control group. All participants received routine care and treatment during the study, and none of the subjects underwent pulmonary rehabilitation

Patient information form. A 15-question form created to obtain the socio-demographic data and chronic disease diagnoses of the patients.

Basal dyspnea index. The data of this study were evaluated with the BDI developed by Mahler et al. ${ }^{9}$ The BDI, which includes the sub-dimension of functional impairment to optimize the clinical measurement of dyspnea, has been adapted to Turkish by many different 
researchers. ${ }^{10,11}$ The BDI score is based on ratings for 3 categories: functional impairment, task size, and effort size. Dyspnea in each category is graded on a 5-point scale from 0 (severe) to 4 (intact). The scores of each category are added to form the total dyspnea score (between 0 and 12). The lower the score, the higher the severity of dyspnea. ${ }^{9}$ The Cronbach alpha value for this study was 0.823 .

Pulmonary function tests. Pulmonary function tests are used in determining the diagnosis, follow-up, severity, and prognosis of the disease in COPD. The most common and reliable parameter is FEV1. The degree of airway obstruction is determined by FEV1. The worse a person's airflow limitations is, the lower the FEV1 value. Forced expiratory volume in 1 tends to decrease as COPD progresses. ${ }^{1}$ The Global Obstructive Lung Disease (GOLD) intervention stages are defined as follows (in patients with FEV1/FVC [forced vital capacity]<0.70): stage II (intermediate), $50 \% \leq \mathrm{FEV} 1<80 \%$ predicted. In this study, PFT values were checked to determine respiratory functions, as well as their contributions to dyspnea.

Self-care management scale in chronic diseases. Self-care management scale is a tool developed by Jones et $\mathrm{al}^{12}$ to evaluate the self-care management process in chronic diseases. Hançerelioğlu and Aykar ${ }^{13}$ translated it into Turkish in 2018 and confirmed its validity and reliability. On this 35-question-scale, 2 types of protection concepts, defined as self-protection (20 items) and social protection (15 items), constitute the 2 sub-dimensions. Items are scored from 5 (strongly agree) to one (never agree) on a 5-point Likert-type scale. As the SCMP-G score increases, self-care management increases. The general Cronbach alpha value of the scale is 0.75 , while 0.78 for self-protection sub-dimension, and 0.78 for social protection sub-dimension. In the present study, the general Cronbach alpha value of the scale is 0.92 , while 0.84 for self-protection sub-dimension and 0.87 for the social protection sub-dimension.

The primary outcome of this study is defined as the changes in dyspnea (as measured by the BDI; the functional impairment, magnitude of task, and magnitude of effort sub-dimensions of the BDI; and changes in PFT) and SCMP-G (the self and social protection sub-dimensions of the SCMP-G) during the 3 months between the start and the end of the study. The secondary outcome is defined as hospitalizations and changes in BMI.

Using $\mathrm{G}^{*}$ Power version 3.1.9.2, the minimum sample size was determined as 15 for an effect size of 0.80 , alpha value of 0.05 and power of 0.80 . More than 15 subjects were included in the study accounting for anticipated loss (paired Wilcoxon signed-rank test). The sample size is 20 in the study group; power analysis result was calculated as power 0.80 , since a significant difference between the scores in tests will be calculated by taking the type I error amount as 0.05 and the medium effect size $(0.5)$. The intention to treat test was performed for patients who leave at any stage of the study from the intervention and control group, the result of test was founded 0.87 (by using the modified intention-to-treat).

Stage II COPD patients that were due for a follow-up one month after discharge from the internal disease clinic were determined. These patients were approached in the outpatient clinic prior to their follow-up examination. Fifty-one conforming patients were included in the study after they were informed regarding the purpose of the study and provided consent. The subjects were randomized into experimental and control groups using a computer-generated random number table. ${ }^{14}$ Numbered opaque envelopes were used to implement the random allocation to conceal the sequence until the subjects were assigned to the 2 groups. For practical reasons, neither patients nor researchers were blinded to the implementation of EBIP. Contact information (telephone number, telephone number of a relative and home address) was obtained. The patients were invited to the internal medicine clinic on specific dates and times.

Blinding and masking. Double blinding is not considered possible for EBIP interventions, where participants and researcher can recognize group assignment. However, giving and scoring the assessments were masked wherever feasible. The assistant researcher who managed and scored the questionnaires and the nurse who made PFT measurements and the physician who made the evaluations were blinded to the experimental groups. Coded answer sheets were analyzed only after the study's completion

Interventions. Intervention and control groups' PFT measurements were made by a PFT nurse working in the outpatient clinic. The participants were informed on the rules, procedures and test maneuvers prior to spirometre. ${ }^{15}$ Pulmonary function test was measured at rest using the ZAN 100 Handy Spirometer (ZAN Messgeräte $\mathrm{GmbH}$, Oberthulba, Germany). The test was repeated 3 times when possible, and the largest FVC + FEV1 sum was used for analysis.

Basal dyspnea index, SCMP-G, and BMI data of all subjects were collected by the face-to-face interview method by a trained assistant researcher who was not involved in the study.

Body mass index was measured using weight and 
height data. Height was measured with a stadiometer (precision of one $\mathrm{cm}$ ) and weight was measured using a standard medical weighing scale (precision of one kg). ${ }^{16}$ The interview was concluded for the control group at this point.

Education-based intervention program was carried out in 3 stages only for the intervention group: i) hospital education; ii) home visits + education; iii) telephone monitoring and guidance. For the purpose of the EBIP, a handbook was used in line with the relevant literature ${ }^{1}$ and opinions received from 2 specialist physicians. The handbook consisted of 4 sections that concerned improving breathing exercises, drug compliance, nutrition, and illness self-care behavior. The trainings sessions were conducted in a hospital seminar room using PowerPoint presentations. Afterward, patients were asked to demonstrate what they learned, and the parts that were not clear were explained again. The training was concluded after deciding for the first home visit appointment. For patients that could not effectively use the handbook, a close relative was included to all steps of the study.

It was observed that available studies did not provide a standard frequency or duration of home visits to COPD patients. ${ }^{17}$ In our study, a total of 3 home visits and contacted all EBIP subjects with phone calls were carried out. The appointments were reminded by a phone call the day before the home visits. The trainings and applications given at home visits were repeated using motivational techniques, the patientcentered approach, in which the patient's knowledge and skill deficiencies were evaluated in accordance with the program and individual needs of the patients, was presented and counseling was provided. At the end of the visits, participants were given an appointment for posttest measurements at the hospital.

After the completion of the education phase, patients were given appointments for posttest BDI, PFT, SCMP-G, and BMI. All 2 researchers conducted the training sessions, and home visits and telephone interviews were conducted by one researcher to minimize any inconsistencies that might be caused by multiple researchers.

Statistical analysis. Data were analyzed using IBM SPSS Statistics for Windows, version 20.0 (IBM Corp, Armonk, NY., USA) and presented in numbers, percentage distributions, and mean ranks. The descriptive characteristics of the 2 groups were

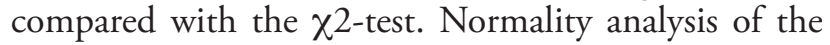
data was determined by Kolmogorov-Smirnov and Shapiro-Wilk tests. The pretest and posttest results were compared using the Mann Whitney U-test and the intergroup changes were evaluated using the Wilcoxon signed-rank test. Statistical significance level is $p<0.05$

Results. Ten of the 61 selected patients were excluded from the study due to not meeting the study criteria. The remaining 51 patients were assigned to randomization groups. The study resulted in 40 patients (Figure 1).

Participants were statistically similar in terms of gender, marital status, smoking status, disease duration, being a chronic disease other than COPD and age (Table 1).

The differences between functional impairment pretest and posttest scores of the patients in the intervention group were found to be significant in favor of the posttest $(p=0.007)$, while the differences between the functional impairment pretest and posttest scores

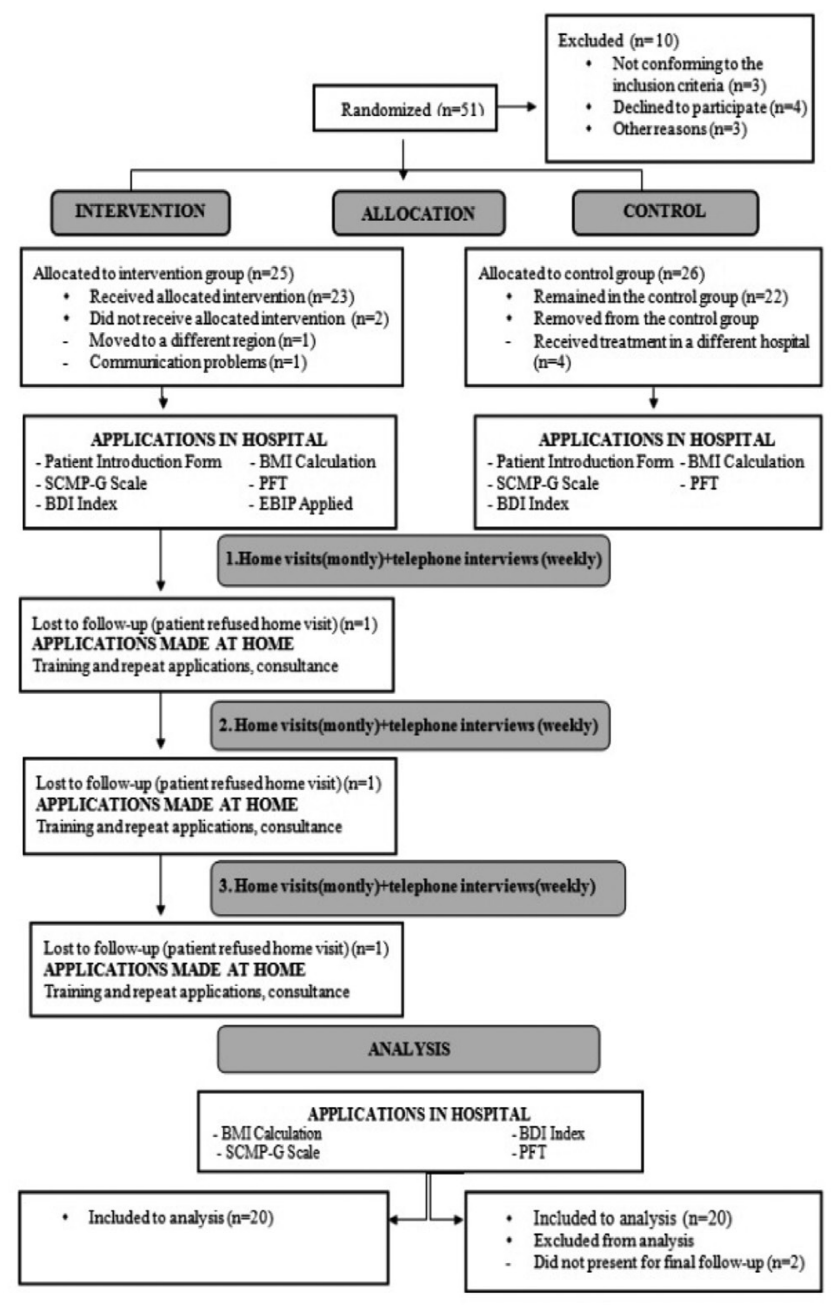

Figure 1 - Study flow chart. 
Table 1 - Comparison of the descriptive characteristics of patients in the intervention and control groups.

\begin{tabular}{|c|c|c|c|}
\hline Characteristics & $\begin{array}{l}\text { Intervention } \\
\quad(\mathrm{n}=20)\end{array}$ & $\begin{array}{l}\text { Control } \\
(\mathrm{n}=20)\end{array}$ & $P$-value \\
\hline \multicolumn{4}{|l|}{ Gender } \\
\hline Female & $9(45.0)$ & $7(35.0)$ & \multirow{2}{*}{$\begin{aligned} \mathrm{x}^{2} & =0.417 \\
p & =0.519\end{aligned}$} \\
\hline Male & $11(55.0)$ & $13(65.0)$ & \\
\hline \multicolumn{4}{|l|}{ Marital status } \\
\hline Married & $19(95.0)$ & $18(90.0)$ & \multirow{2}{*}{$p=1.000^{*}$} \\
\hline Single & $1 \quad(5.0)$ & $2(10.0)$ & \\
\hline \multicolumn{4}{|l|}{ Smoking status } \\
\hline I use & $5(25.0)$ & $4(20.0)$ & \multirow{3}{*}{$\begin{array}{c}\mathrm{x}^{2}=0.926, \\
p=0.629\end{array}$} \\
\hline I drank, I quit & $7(35.0)$ & $10(50.0)$ & \\
\hline I’ve never drunk & $8(40.0)$ & $6(30.0)$ & \\
\hline \multicolumn{4}{|c|}{ Duration of the disease } \\
\hline $0-5$ years & $15(75.0)$ & $9(45.0)$ & \multirow{2}{*}{$\begin{array}{c}\mathrm{x}^{2}=3.750, \\
p=0.053\end{array}$} \\
\hline 6 years and more & $5(25.0)$ & $11(55.0)$ & \\
\hline \multicolumn{4}{|c|}{ Chronic disease outside COPD } \\
\hline There is & $5(25.0)$ & & \multirow{2}{*}{$p=0.047^{*}$} \\
\hline There isn't & $15(75.0)$ & $20(100)$ & \\
\hline Age $($ mean $\pm S D)$ & $66.50 \pm 9.36$ & $61.35 \pm 13.71$ & $\begin{array}{c}\mathrm{Z}=-1.222, \\
p=0.231\end{array}$ \\
\hline $\begin{array}{l}\text { Values are present } \\
\text { shown bec }\end{array}$ & $\begin{array}{l}\text { number and } \\
\text { Fisher's exact }\end{array}$ & $\begin{array}{l}\text { centages }(\%) \text {. } \\
\text { i square test is }\end{array}$ & $\begin{array}{l}\text { value is no } \\
\text { lied. }\end{array}$ \\
\hline
\end{tabular}

of the patients in the control group were found to be insignificant $(p=0.060)$. The differences between the task size pretest and posttest scores of the patients in the experimental group were found to be significant in favor of the posttest ( $p=0.035$ ), while the differences between the task size on test and posttest scores of the patients in the control group were found to be insignificant $(p=0.490)$. The difference between the effort size pretest and posttest scores of the patients in the intervention group was found to be significant in favor of the posttest $(p=0.001)$, while the differences between the effort size pretest and posttest scores of the patients in the control group were found to be significant against the posttest $(p=0.020)$. The differences between the total points pretest and posttest scores of the patients in the intervention group were also found to be significant in favor of the posttest $(p=0.000)$, while the differences between the total points pretest and posttest scores of the patients in the control group were found to be significant against the posttest $(p=0.001)$. These findings show that EBIP applied to the intervention group has positive effects on the functional impairment, task size, effort size and total points of the patients (Table 2).

The differences between the FEV1\% predict-pretest and posttest scores of the patients in the intervention group were found to be significant in favor of the
Table 2 - Comparison of the Basal dyspnea index scores of the patients in the intervention and control groups before and after the test.

\begin{tabular}{|c|c|c|c|c|}
\hline \multirow[t]{2}{*}{ Variables } & \multirow[t]{2}{*}{$\begin{array}{l}\text { Measuring } \\
\text { time }\end{array}$} & $\begin{array}{l}\text { Intervention } \\
\quad(\mathrm{n}=20)\end{array}$ & $\begin{array}{l}\text { Control } \\
(n=20)\end{array}$ & \multirow[t]{2}{*}{$P$-value ${ }^{\dagger}$} \\
\hline & & Mean rank & Mean rank & \\
\hline \multicolumn{5}{|c|}{ Basal dyspnea index } \\
\hline \multirow{3}{*}{$\begin{array}{l}\text { Functional } \\
\text { impairment }\end{array}$} & Pretest & 18.63 & 22.36 & \multirow{3}{*}{$\begin{aligned} \mathrm{z} & =-1.254, \\
p & =0.210 \\
\mathrm{z} & =-2.584, \\
p & =0.010\end{aligned}$} \\
\hline & Posttest & 25.03 & 15.98 & \\
\hline & $P$-value* & $\begin{array}{c}\mathrm{Z}=-2,714, \\
p=0.007\end{array}$ & $\begin{array}{c}Z=-2.584, \\
p=0.060\end{array}$ & \\
\hline \multirow{3}{*}{ Task size } & Pretest & 16.25 & 24.75 & \multirow{3}{*}{$\begin{array}{c}\mathrm{z}=-2.652, \\
p=0.008 \\
\mathrm{z}=-0.694, \\
p=0.488\end{array}$} \\
\hline & Posttest & 19.30 & 21.70 & \\
\hline & $P$-value* & $\begin{array}{c}\mathrm{Z}=-2.111, \\
p=0.035\end{array}$ & $\begin{array}{c}\mathrm{Z}=-0.707, \\
p=0.490\end{array}$ & \\
\hline \multirow{3}{*}{ Effort size } & Pretest & 17.95 & 23.05 & \multirow{3}{*}{$\begin{array}{c}\mathrm{z}=-1.707, \\
p=0.088 \\
\mathrm{z}=-1.955, \\
p=0.051\end{array}$} \\
\hline & Posttest & 23.88 & 17.13 & \\
\hline & $P$-value* & $\begin{array}{c}\mathrm{Z}=-3.317 \\
p=0.001\end{array}$ & $\begin{array}{c}\mathrm{Z}=-2.333 \\
p=0.020\end{array}$ & \\
\hline \multirow{3}{*}{ Total points } & Pretest & 16.48 & 24.53 & \multirow{3}{*}{$\begin{array}{c}\mathrm{z}=-2.331, \\
p=0.020 \\
\mathrm{z}=-2.356, \\
p=0.018\end{array}$} \\
\hline & Posttest & 24.73 & 16.28 & \\
\hline & $P$-value* & $\begin{array}{c}\mathrm{Z}=-3.562 \\
p=0.000\end{array}$ & $\begin{array}{c}\mathrm{Z}=-3.214 \\
p=0.001\end{array}$ & \\
\hline
\end{tabular}

* Two Wilcoxon paired sample tests were used. $†$ Mann-Whitney U test was used.

posttest $(\mathrm{Z}=-3.103, p=0.002)$, while the differences between the FEV1\% predict-pretest and posttest scores of the patients in the control group were found to be insignificant $(Z=-0.422, p=0.673)$. The differences between the FVC predict pre-test and posttest scores of the patients in the intervention group were found to be significant $(\mathrm{Z}=-1.923, p=0.055)$, while the differences between the FVC predict-pre-test and posttest scores of the patients in the control group were found to be significant $(Z=-3.585, p=0.000)$. The differences between the FEV1/FVC \% pretest and posttest scores of the patients in the intervention group were found to be significant in favor of the posttest $(Z=-3.666, p=0.000)$, while the differences between the FEV 1/FVC \% pretest and posttest scores of the patients in the control group were found to be significant against the posttest $(\mathrm{Z}=-2.271, p=0.023)$. These findings indicate that EBIP applied to the intervention group has positive effects on the patients' FEV1\% predict, FVC and FEV1/FVC \% (Table 3).

As presented in Table 4, the total SCMP-G scores 
$(Z=-3.921, \quad p=0.000)$, self protection $(Z=-2.507$, $p=0.012)$, and social protection $(Z=-3.924, p=0.000)$ sub-dimension scores of the intervention group increased. The difference between the pretest and posttest results was statistically significant. There was no significant difference in the total SCMP-G score and the related sub-dimension scores of the control group. When the pretest and posttest SCMP-G scores of the 2 groups were compared; posttest scores (total, self-protection, social protection) were found to be statistically significant in the intervention group $(p=0.000)$.

Although the number of hospital admissions of the patients in the control group was higher, the difference between the 2 groups was not statistically significant $(p=0.185)$. The pretest and posttest BMI results of the 2 groups were evaluated. It was observed that the mean rank BMI of the intervention group significantly decreased following EBIP $(p=0.002)$. The mean rank posttest BMI of the control group was higher than pretest BMI, but this difference was not statistically significant $(p=0.088)$. The differences between the $\operatorname{EBIP}(p=0.148)$ and control mean rank $(p=0.123)$ BMI values were not significantly different before or after the trial (Table 5).

Study limitations. The results of the study cannot be generalized to all stages of COPD, as it only includes stage II COPD patients. In addition, we limited our subjects to patients that were treated for stage II COPD less than one month before and that came in for follow-up examinations. Re-hospitalization due to exacerbations is common within one month after

Table 3 - Comparison of Pulmonary Function Tests scores averages of patients in the intervention and control groups before and after the test

\begin{tabular}{|c|c|c|c|c|}
\hline \multirow{2}{*}{\multicolumn{2}{|c|}{ Variables }} & Intervention $(\mathrm{n}=20)$ & Control(n=20) & \multirow{2}{*}{$P$-value ${ }^{\dagger}$} \\
\hline & & Mean rank & Mean rank & \\
\hline \multicolumn{5}{|c|}{ Pulmonary function tests } \\
\hline \multirow{4}{*}{$\begin{array}{l}\text { FEV1\% } \\
\text { predict }\end{array}$} & Pretest & 19.40 & 21.60 & $\mathrm{z}=-0.595, p=0.552$ \\
\hline & Posttest & 21.80 & 19.20 & $\mathrm{z}=-0.704, p=0.482$ \\
\hline & $P$-value ${ }^{*}$ & $Z=-3.103, p=0.002$ & $Z=-0.422, p=0.673$ & \\
\hline & Pretest & 19.15 & 21.85 & $\mathrm{z}=-0.731, p=0.465$ \\
\hline \multirow{3}{*}{ FVC } & Posttest & 20.05 & 20.95 & $\mathrm{z}=-0.243, p=0.808$ \\
\hline & $P$-value ${ }^{*}$ & $Z=-1.923, p=0.055$ & $\mathrm{Z}=-3.585, p=0.000$ & \\
\hline & Pretest & 16.73 & 24.28 & $\mathrm{z}=-2.045, p=0.041$ \\
\hline \multirow[t]{2}{*}{ FEV1/FVC \% } & Posttest & 17.70 & 23.30 & $\mathrm{z}=-1.517, p=0.129$ \\
\hline & $P$-value ${ }^{*}$ & $\mathrm{Z}=-3.666, p=0.000$ & $\mathrm{Z}=-2.271, p=0.023$ & \\
\hline
\end{tabular}

${ }^{*}$ Two Wilcoxon paired sample tests were used. †Mann-Whitney $U$ test was used. FEV1: forced expiratory volume in one second, FVC: forced vital capacity

Table 4 - Comparison of self-care management scale in chronic diseases (SCMP-G) mean rank scores before and after the tests of patients in the intervention and control groups.

\begin{tabular}{lcccc}
\hline \multirow{2}{*}{ Variables } & $\begin{array}{c}\text { Measuring } \\
\text { time }\end{array}$ & $\begin{array}{c}\text { Intervention(n=20) } \\
\text { Mean rank }\end{array}$ & $\begin{array}{c}\text { Control(n=20) } \\
\text { Mean rank }\end{array}$ & $P_{\text {-value }}^{\dagger}$ \\
\hline \multirow{3}{*}{ Self protection } & Pretest & 29.35 & 11.65 & $\mathrm{z}=-4.795, p=0.000$ \\
& Posttest & 30.50 & 10.50 & $\mathrm{Z}=-5.422, p=0.000$ \\
& $P$-value & $\mathrm{Z}=-2.507, p=0.012$ & $\mathrm{Z}=-0.549, p=0.583$ & \\
\multirow{3}{*}{ Social protection } & Pretest & 20.05 & 20.95 & $\mathrm{Z}=-0.244, p=0.807$ \\
& Posttest & 30.50 & 10.50 & $\mathrm{Z}=-5.423, p=0.000$ \\
& $P$-value & $\mathrm{Z}=-3.924, p=0.000$ & $\mathrm{Z}=-0.277, p=0.782$ & \\
\multirow{3}{*}{ SCMP-G total } & Pretest & 27.95 & 13.05 & $\mathrm{Z}=-4.036, p=0.000$ \\
& Posttest & 30.50 & 10.50 & $\mathrm{Z}=-5.421, p=0.000$ \\
& $P$-value & $\mathrm{Z}=-3.921, p=0.000$ & $\mathrm{Z}=-0.575, p=0.565$ & \\
\hline
\end{tabular}

* Two Wilcoxon paired sample tests were used. †Mann-Whitney U test was used. 
Table 5 - Comparison of admission to hospital and body mass index mean rank scores of patients in the intervention and control groups before and after the tests.

\begin{tabular}{lcccc}
\hline Variables & & $\begin{array}{c}\text { Intervention }(\mathbf{n}=20) \\
\text { Mean rank }\end{array}$ & $\begin{array}{c}\text { Control }(\mathbf{n}=20) \\
\text { Mean rank }\end{array}$ & $P^{\text {-value }^{\dagger}}$ \\
\hline Admission to the & No & $15(75.0)$ & $11(55.0)$ & $\mathrm{x}^{2}=1.758, p=0.185$ \\
hospital $^{\S}$ & Yes & $5(25.0)$ & $9(45.0)$ & $\mathrm{z}=-1.447, p=0.148$ \\
\multirow{3}{*}{ Body mass index } & Pretest & 17.83 & 23.18 & $\mathrm{z}=-1.542, p=0.123$ \\
& Posttest & 17.65 & 23.35 & \\
& $P_{\text {-value }}^{*}$ & $\mathrm{Z}=-3.026, p=0.002$ & $\mathrm{Z}=-1.708, p=0.088$ & \\
\hline
\end{tabular}

* Two Wilcoxon paired sample tests were used. $†$ Mann-Whitney U test was used. §Number of people who applied to the hospital only for COPD during the study.

discharge. ${ }^{6}$ Therefore, it is important to improve patients' compliance to treatment and management of chronic disease after discharge and to support this with planned interventions. ${ }^{1,6}$ The strengths of this study are it is randomized, controlled, and single-blined, with a good methodology.

Discussion. This research showed advantages over the short term (3 months) compared to usual care in improving EBIP, dyspnea, and chronic disease self-care management in the intervention group. Our results after 3 months partially support H1 (EBIP improves dyspnea) and strongly support H2 (EBIP improves chronic self-care management). Research shows that in patients with moderate COPD $(50 \% \leq \mathrm{FEV} 1<80 \%$ predicted), physical and breathing exercises reduce dyspnea and improve respiratory functions, body weight, and quality of life, but it is necessary to maintain structured programs to achieve these outcomes, which must include self-care education in addition to routine care. ${ }^{18,19}$ One study found that visiting patients and their families outside the hospital setting and in their homes provides convenience for the patient, strengthens cooperation and can motivate proactivity and compliance. ${ }^{20}$ One of the advantages of EBIP is its face-to-face nature and the consequent opportunity to address individual problems and integrate them to the process. ${ }^{21}$ However, this program may have limited applicability in regions where the number of nurses is limited or where home visits are problematic due to security. The subsequently increased probability of noncompliance to the determined home visit and phone appointment schedule will impair the effectiveness of the study design.

The total BDI scores and the functional impairment and effort size sub-dimension results were significantly different for the 2 groups ( $p<0.05$, Table 2$)$. The task size sub-dimension scores were also higher in the intervention group, but this difference was not statistically significant $(p>0.05)$. Certainly, EBIP improved BDI scores overall, even if not in all sub-dimensions. Studies indicated that structured training programs that often include nurses, nursing care and training in the form of home visits and telephone calls, inhaler use training, and self-management training programs that include the correct use of drugs, all contribute to the management of COPD symptoms, primarily dyspnea., 18,22-24 Our results are consistent with the literature in that patient training improved dyspnea outcomes. Researchers emphasize the importance combining PFT results with specific and objective scales in diagnosing and evaluating dyspnea. ${ }^{25}$ It is also reported that BDI is associated with PFT, that reduced dyspnea and FEV1 improve increased 5-years survival, and that decreased FEV1 is associated with more severe dyspnea (Table 3). ${ }^{20,26,27}$

The efficiency of theEBIP significantly improved both SCMP-G scores and the scores of its sub-dimensions; statistically significant differences between the intervention and control groups were proved $(p=0.001$, Table 4). The assessment of patients' current levels of self-care improves their health outcomes, as does the education of patients. ${ }^{28-30}$ The interventions of nurses play an important role in supporting and motivating patients, with researchers indicating that nursing care at home increases the power of individual care among COPD patients, and that self-management education of COPD patients given by a COPD-nurse reduces frequency of hospitalizations associated with acute exacerbations and enhances quality of life for patients. ${ }^{31-33}$ In this respect, our findings are consistent with the literature.

The weight status of the patient significantly affects COPD outcomes. ${ }^{34}$ Studies show that being under- or over-weight is closely associated with early stages of COPD. Two separate studies found that the prevalence of obesity was the highest in GOLD 1 and 2 patients. ${ }^{35,36}$ 
We found that the mean BMI of both patient groups were above 25 , and that $22.5 \%$ of all subjects were obese. Healthy and appropriate body weight is good for the long-term management of COPD patients. ${ }^{37}$ In this study, the BMI difference before and after the training in the intervention group was statistically significant $(p=0.002$, Table 5$)$. However, the mean BMI values of the 2 groups were not significantly different before or after the trial. Studies reported different outcomes for BMI after structured interventions. One study found that exercise capacity and disease management of individuals with COPD increased regardless of BMI, whereas another reported that obesity did not negatively impact exercise capacity after pulmonary rehabilitation. ${ }^{38,39}$ The different results may be due to differences in samples and duration of intervention in the studies. Further studies are needed to accurately evaluate the relationship between BMI, and nonpharmacological interventions and education.

In conclusion, this study showed that providing and reinforcing EBIP for 3 months among recently discharged stage II COPD patients provided partial improvement in dyspnea and a significant improvement in self-care management. Advances in secondary outcomes have revealed that this intervention has some repercussions. However, it is recommended to conduct studies evaluating the results of larger samples and education covering all stages of COPD in the long term.

\section{Acknowledgment. We would like to thank Can Translation Center-CTM (https://www.cantercume.com.trl) for English language editing. We would also like to thank Dr. Eray Atalay, Department of Internal Medicine, Kafkas University Hospital, Turkey for her help and support.}

\section{References}

1. Global Initiative for Chronic Obstructive Lung Disease. Pocket Guide to COPD Diagnosis, Management, and Prevention, A Guide for Health Care Professionals. [Updated 2020. Accessed 2019 November 25]. Available from URL: https:/goldcopd. org/wp-content/uploads/2019/12/GOLD-2020-FINALver1.2-03Dec19_WMV.pdf

2. Kantatong T, Panpanich R, Deesomchok A, Sungkarat S, Siviroj P. Effects of the tai chi qigong programme on functional capacity, and lung function in chronic obstructive pulmonary disease patients: A ramdomised controlled trial. J Tradit Complement Med 2020; 10: 345-359.

3. Marciniuk DD, Goodridge D, Hernandez P, Rocker G, Balter M, Bailey P, et al. Managing dyspnea in patients with advanced chronic obstructive pulmonary disease: A Canadian thoracic society clinical practice guideline. Can Respir J 2011; 18: 69-78.

4. Nabais A, Céu Sá M. The patient with chronic obstructive pulmonary disease: how rehabilitation nurses promote self-care. Millenium-Journal of Education, Technologies, and Health 2019; 2: 93-101.
5. Turkish Thoracic Society Pulmonary Rehabilitation Pocket Book. Turkish Thoracic Society. Istanbul. [Updated 2019. Accessed 2019 November 25]. Available from URL: https:// toraks.org.tr/site/downloads/73nlRwTyhPD9Fkc8

6. McCarthy B, Casey D, Devane D, Murphy K, Murphy E, Lacasse Y. Pulmonary rehabilitation for chronic obstructive pulmonary disease. Cochrane Database Syst Rev 2015; 2: 1-186

7. Lenferink A, Brusse-Keizer $M$, van der Valk PD, Frith PA, Zwerink M, Monninkhof EM et al. Self-management interventions including action plans for exacerbations versus usual care in patients with chronic obstructive pulmonary disease. Cochrane Database Syst Rev 2017; 8: CD011682.

8. Helvaci A, Gok MZ, Ozdemir L, Ergun P. The effects of a nurse-led education and counseling program on dyspnea, health status, and care dependency in patients with chronic obstructive pulmonary disease: A feasibility study. SAGE 2019; 31: 249-256.

9. Mahler DA, Weinberg DH, Wells CK, Feinstein AR. The measurement of dyspnea: contents, interobserver agreement, and physiologic correlates of two new clinical indexes. Chest 1984; 85: 751-758.

10. Demir G, Akkoca Ö, Doğan R, Saryal S, Karabiyikoğlu G. The evaluation of dyspnea and quality of life in COPD. Tüberküloz ve Toraks Dergisi 2003; 51:365-372.

11. Özalevli S, Uçan ES. Comparison of the different dyspnea scales in chronic obstructive pulmonary disease. Toraks Dergisi 2004; 5: 90-94.

12. Jones LC, Hill K, Honer K, McDaniels S. Self-care management process used by individuals with chronic illness. Unpublished manuscript. 1986.

13. Hançerlioğlu S, Aykar FŞ. Validity and Reliability of Turkish Version of the Self Care Management Process in Chronic Illness. GUSBD 2018; 7: 175-183.

14. Research Randomizer. Generate Numbers [Updated 2020. Accessed 2019 November 24]. Available from URL: http:// www.randomizer.org

15. Global Initiative for Chronic Obstructive Lung Disease. Global strategy for the diagnosis, management and prevention of chronic obstructive pulmonary disease. [Updated 2020. Accessed 2019 January 25]. Available from URL: http=//www. goldcopd.org/

16. World Health Organization. Body mass index-BMI. [Updated 2020. Accessed 2019 January 25] Available from URL: http:// www.euro.who.int/en/health-topics/disease-prevention/ nutrition/a-healthy-lifestyle/body-mass-index-bmi

17. Baker E, Fatoye F. Patient perceived impact of nurse-led selfmanagement interventions for COPD: A systematıc review of qualitative research. Int J Nurs Stud 2019; 91: 22-34.

18. Aytac SO, Kilic SP, Ovayolu N. Effect of inhaler drug education on fatigue, dyspnea severity, and respiratory function tests in patients with COPD. Patient Educ Couns 2020; 103: 709-716.

19. Dehkordi AH, Ebrahimi-Dehkordi S, Banitalebi-Dehkordi F, Tali SS, Kheiri S, Babadi AS. The effect of teach-back training intervention of breathing exercise on the level of dyspnea, six-minutes walking test and FEV1/FVC ratio in patients with chronic obstructive pulmonary disease; a randomized controlled trial. Expert Rev Respir Med 2020; 29: 1-9.

20. Dainty KN, Seaton MB, Drennan IR, Morrison LJ. Home visit-based community paramedicine and its potential role in improving patient-centered primary care: a grounded theory study and framework. Health Serv Res 2018; 53: 3455-3470. 
21. Thom DH, Grace RW, Tsao S, Hessler D, Huang B, DeVore $\mathrm{D}$, et al. Randomized controlled trial of health coaching for vulnerable patients with chronic obstructive pulmonary disease. Ann Am Thorac Soc 2018; 15: 1159-1168.

22. Sunde S, Walstad RA, Bentsen SB, Lunde SJ, Wangen EM, Rustøen T, et al. The development of an integrated care model for patients with severe or very severe chronic obstructive pulmonary disease (COPD: the COPD-Home model. Scand J Caring Sci 2014; 28: 469-477.

23. Kim YM, Yu M, Moon HR, Ju SY, Lee GA, Kim MJ. Effects of a tailored inhaler use education program for chronic obstructive pulmonary disease patients. Patient Educ Couns 2020; 103: 717-723.

24. Moriyama M, Takeshita Y, Haruta Y, Hattori N, Ezenwaka CE. Effects of a 6 month nurse-led self- management program on comprehensive pulmonary rehabilitation for patients with COPD receiving home oxygen therapy. Rehabil Nurs2015; 40: 40-51.

25. Kara D, Yıldız H. Effectıveness and frequencies of dyspnea scales in evaluatıng symptom of dyspnea. Gümüshane Universitesi Sağlık Bilimleri Dergisi 2013; 2: 137-49.

26. Almagro P, Martinez PC, Soriano JB, Marin JM, Alfageme I, Casanova $\mathrm{C}$, et al. Finding the best thresholds of FEV1 and dyspnea to predict 5-year survival in COPD patients: the Cocomics study. PLoS One 2014; 9: e89866.

27. Diago CAA, Maestu LP, Bolado BA, Calvo JA, Hernando MH, Bats IP, et al. Translation and validation of the multidimensional dyspnea-12 questionnaire. Archivos de Bronconeumología (English Edition) 2018; 54: 74-78.

28. Clari M, Matarese M, Ivziku D, Marinis MG. Self-care of people with chronic obstructive pulmonary disease: A metasynthesis. Patient 2017; 10: 407-427.

29. Park SK. Factors affecting self-care behavior in Koreans with COPD. Appl Nurs Res 2017; 38: 29-37.

30. Baker E, Fatoye F. Clinical and cost-effectiveness of nurse-led self-management interventions for patients with COPD in primary care: A systematic review. Int J Nurs Stud 2017; 71: $125-138$.
31. Özkaptan BB, Kapucu S. Home nursing care with the self-care model improves self-efficacy of patients with chronic obstructive pulmonary disease. Jpn J Nurs Sci 2016; 13: 365-377.

32. Wang LH, Zhao Y, Chen LY, Zhang L, Zhang YM. The effect of a nurse-led self-management program on outcomes of patients with chronic obstructive pulmonary disease. Clin Respir J 2020; 14: 148-157

33. Folch-Ayora A, Orts-Cortés MI, Macia-Soler L, AndreuGuillamon MV, Moncho J. Patient education during hospital admission due to exacerbation of chronic obstructive pulmonary disease: effects on quality of life-controlled and randomized experimental study. Patient Educ Couns 2019; 102: 511-519.

34. Broderick J, Mc Grath C, Cullen K, Talbot D, Gilmor J, Scanlan BM, et al. Effects of pulmonary rehabilitation on exercise capacity and disease impact in patients with chronic obstructive pulmonary disease and obesity. Physiotherapy 2018; 104: 248-250.

35. Katz P, Iribarren C, Sanchez G, Blanc PD. Obesity and functioning among individuals with Chronic Obstructive Pulmonary Disease (COPD). COPD 2016; 13: 352-359.

36. Zewari S, Hadi L, van den Elshout F, Dekhuijzen R, Heijdra Y, Vos P. Obesity in COPD: comorbidities with practical consequences?. COPD 2018; 15: 464-471.

37. Wu Z, Yang D, Ge Z, Yan M, Wu N, Liu Y. Body mass index of patients with chronic obstructive pulmonary disease is associated with pulmonary function and exacerbations: a retrospective real world research. J Thorac Dis 2018; 10: 5086.

38. Pierobon A, Bottelli ES, Ranzini L, Bruschi C, Maestri R, Bertolotti G. et al. COPD patients' self-reported adherence, psychosocial factors and mild cognitive impairment in pulmonary rehabilitation. Int J Chron Obstruct Pulmon Dis 2017; 12: 2059-2067.

39. Broderick J, Mc Grath C, Cullen K, Talbot D, Gilmor J, Baily-Scanlan M. Et al. Effects of pulmonary rehabilitation on exercise capacity and disease impact in patients with chronic obstructive pulmonary disease and obesity. Physiother 2018; 104: $248-250$. 